\title{
METRIC ANALYSIS OF SEXUAL DIMORPHISM IN NORTH INDIAN
} PELVIC INDICES

\section{Kanika Sachdeva *1, Rajan Kumar Singla ${ }^{2}$, Gurdeep Kalsey ${ }^{3}$.}

${ }^{* 1}$ Associate Professor, Department of Anatomy, SGRDIMSAR, Amritsar, Punjab, India.

2 Professor \& Head, Department of Anatomy, Government Medical College, Patiala, Punjab, India.

${ }^{3}$ Retired Professor \& Head, Department of Anatomy, Government Medical College, Amritsar, Punjab, India.

\section{ABSTRACT}

Background: Skeleton is an excellent investigating material in living and non-living population for genetic, anthropological and forensic purposes. Anatomical knowledge of human osteology, in the evaluation of death may help to shed light on legal issues such as sex and age determination, parentage and racial identity. With racial differences, it's difficult to implement a uniform method for determining sex. Therefore, the need for present study was felt. Many bones of skeleton present size related sexual differences, those of the pelvis usually displayed differences in morphology independent of size as the sex hormones influence the reproductive functions. In the present study an attempt has been made to arrive at appropriate metric data, regarding sex determination of North Indian pelves using indices calculated upon dry hip bones, sacrum \& pelvis as a whole.

Materials and Methods: The study was conducted on 50 adult pelvis (M: $F=40: 10$ ) obtained from Government Medical College, Amritsar. Measurements related to Pelvic Brim Index, Coxal Index, Index I \& Index II of Greater Sciatic Notch, Ischiopubic Index, Sacral index, Longitudinal Curvature index \& Corporobasal index were taken by standardized methods, indices were calculated \& results were statistically analyzed.

Results: Amongst the various indices calculated in present study Coxal Index, Index I \& Index II of Greater Sciatic Notch, Ischiopubic Index \& Sacral index were found to be significantly sexually dimorphic.

Conclusions: Since skeletal characteristics vary among populations; therefore the present study provides a database for various significant pelvis related indices amongst North Indian population to optimize the accuracy of sex identification.

KEY WORDS: Sexual dimorphism, Forensic, Anthropologists, Orthopaedicians, Hip bone, Pelvis, Sacrum, Index.

Address for Correspondence: Dr Kanika Sachdeva, Associate Professor, Department of Anatomy, SGRDIMSAR, Amritsar, Punjab, India.+91-9888284878, E Mail: kanikadr.sarang@yahoo.com

Access this Article online Quick Response code

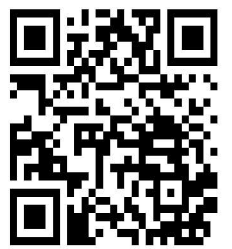

DOI: $10.16965 /$ ijar.2019.118

Journal Information

International Journal of Anatomy and Research

ICV for 2016
90.30
ISSN (E) 2321-4287 | ISSN (P) 2321-8967 https://www.ijmhr.org/ijar.htm DOI-Prefix: https://dx.doi.org/10.16965/ijar

\section{Article Information}

Received: 23 Jan 2019

Peer Review: 24 Jan 2019

Revised: None
Accepted: 07 Mar 2019

Published (O): 05 Apr 2019

Published (P): 05 Apr 2019

\section{INTRODUCTION}

Human identification by forensic experts is often the first step in the process of identification of victims following natural disasters, air crashes, murders, explosions and mass fatality events [1-3]. In such situations; age, sex, stature and ethnic background are the four main features of biological identity where remained body parts can be used for identification [4].

Bones are the hardest and most durable structures of the body, and are the last to decay after death, next to enamel of teeth. Hence, the skeletal materials are used in establishing the personal identity by medico legal experts, 
anatomist and anthropologist for giving their opinion with respect to sex, age and stature of the deceased [5].

The body segments characteristics are different in different populations and so their dimensions can be used for predicting the stature or sex. In this regard, pelvis was the first topic of interest [6].

The sex differences in pelvis can result from genetic factors, environmental factors affecting growth and development (nutrition, physical activity, and pathologies), and the interaction of these factors [7]. Like any other bone, pelvic bone too isn't free of debate when it comes to sex determination using the bone [8]. Primarily, the human pelvis was shaped by the erect posture and the bipedal locomotion [9]. Secondarily, the female pelvis was exposed to an additional selective pressure of the obstetric difficulties caused by the encephalization of a newborn $[10,11]$.

The pelvic girdle consists of the two hip bones and the sacrum. It is massively constructed and serves as a weight bearing and protective structure [12]. The shape and size of the hip bones are influenced by hormonal, nutritional, mechanical and hereditary factors [13].

Sacrum, as a part of pelvis also demonstrates sex differences. Both the hip bone $[14,15]$ \& sacrum [16] exhibit sexual dimorphism as a special adaptation in females for child bearing.

Population-specific skeletal characteristics develop in societies. Sex specific features are inevitably clustered into these populations. Therefore, population and sex-specific studies are indispensable $[17,18]$. Due to the regional variability identification standards cannot be applied across population, which call for group specific standards, to optimize the accuracy of identification [14].

An attempt has been made in this study to arrive at appropriate conclusions regarding sex determination using various indices of hip bones, sacrum \& pelvis representing North Indian population. An awareness of the average values of the sexually dimorphic indices will help in early detection of disputed sex by forensic experts and would also provide valuable parameters for the anthropologists and orthopaedicians.

\section{MATERIALS AND METHODS}

A cross-sectional, analytical type of study was conducted on 50 adult bony pelves ( 40 male \& 10 female) of the known sex but of unknown age, obtained from Department of Anatomy, Govt. Medical College, Amritsar. These pelves were cleaned and boiled to an extent that the sacroiliac joints should not open. The boiled pelves were dried in open sunshine. Any disarticulated joints were fixed with appropriate adhesive substance (elfy). The pelves selected were without any gross abnormality and were complete in all respects to give correct measurements. The specific measurements of hip bone, sacrum and pelvis; required for the calculation of various indices; were taken by the well documented methods and are mentioned along with the respective indices.

Following indices of pelves were calculated and recorded, all expressed in percentage

Pelvic brim Index= ( Anatomical conjugate) Maximum transverse Diameter of Brim)X100 [19]

Anatomical conjugate (True conjugate) - It was taken with the help of vernier callipers from the upper inner border of the symphyseal face to the centre of the sacral promontory on both the sides (CD \& CD' in Fig. 1) and their average was taken.

Transverse diameter of the inlet-It is the greatest diameter between the arcuate lines at right angles to the anatomical conjugate $(A B$ in Fig. 1). It was recorded with the help of a divider.

Coxal Index = (Iliac Breadth/Maximum Length of Hip Bone)X 100 [20]

Iliac Breadth: - It is the distance between anterior superior iliac spine and the posterior superior iliac spine [21] (BX' in Fig. 2). It was recorded with the help of divider and read on a centimeter scale.

Maximum length of hip bone [20]: It is the maximum distance between the iliac crest and ischial tuberosity of the same side [22] (AC in Fig. 2). It was recorded on osteometric board.

\section{Index of greater sciatic Notch:}

Index I = (Depth of Notch/Width of Notch)X 100 Index II = (Posterior Segment Width/ Width of Notch) X 100 
Width of greater sciatic notch - For measuring this length, different methods have been described by different workers:

Jovanovic and Zivanovic (1965) [23] pointed out that since during preparation of hip bones, most of the times tip of the ischial spine gets broken, so it should be taken between the lower point of posterior superior iliac spine and most medial point on the inside ridge of ischial tuberosity ( $X^{\prime} Y^{\prime}$ in Fig. 2).

Day and Wilmott (1975), [24] Singh \& Potturi (1978), [25] Davivongs (1963) [20], Maclaughling and Bruce (1986) [26] measured it as the distance between the tip of ischial spine and the pyramidal process of the posterior border of the ilium (XY in Fig. 2).

In the present study this measurement was taken as suggested by both methods separately with the help of vernier callipers on both the sides.

Depth of the greater sciatic notch - It is the shortest distance between the deepest point of the concavity of greater sciatic notch and its width line [20]. For recording it, a steel bar was fixed touching the tip of ischial spine and pyramidal process of posterior border of the ilium thus representing the width of greater sciatic notch as per method ' $b$ ' above and then the shortest distance between this bar and deepest point of greater sciatic notch was taken with the help of vernier callipers on both the sides ( $O^{\prime} P$ in Fig. 2). It was also taken as per method ' $a$ ' above ( $O$ ' $P$ ' in Fig. 2).

Posterior segment width - This denotes the length of the posterior segment of the width of greater sciatic notch where the depth line cuts the width line. This was taken in the present study by two methods where two widths of greater sciatic notch were considered and corresponding widths of posterior segment were taken with the help of steel bar and vernier callipers ( $X^{\prime} P^{\prime}$ and $X P$ in Fig. 2).

Ischiopubic index $=$ (Pubic Length/ Ischial Length) X100 [20]

Pubic Length- It is the greatest distance of the central point of the acetabulum from the symphyseal surface of the body of pubis [21] (OD in Fig. 2). It was recorded with the help of verniner callipers on both the sides.
Ischial Length - Seidler (1980) [21] described it as the greatest distance between the central point of acetabulum and the farthest point on inferior aspect of ischial tuberosity which has been named ischial point by Thieme (1957) [27] (OC in Fig.2). It was recorded with the help of vernier callipers on both the sides.

Sacral index $=$ (Anterior straight breadth of sacrum/ Midventral straight length of sacrum)X100 [28]

Midventral straight length of sacrum (Length of the sacral Axis):- It is the length of a straight line drawn from the midpoint on the anterior margin of the sacral promontory to the middle of anteroinferior border of the fifth sacral vertebra [22] (EF in Fig. 3). This measurement was taken with the help of vernier callipers.

Anterior straight breadth of sacrum: - It is the length of straight line drawn across the ventral surface of the first sacral vertebra between the widest margins of lateral wings [28] (MN in Fig. 3). This diameter was recorded with the help of divider and read on a centimeter scale.

Longitudinal curvature index $=$ (Midventral Straight length of sacrum/ Midventral curved length of sacrum) X100 [28,29]

Midventral curved length of sacrum: - It is the length of the curved median line drawn along ventral surface from the middle of sacral promontory to midpoint of anteroinferior border of $5^{\text {th }}$ sacral vertebra (EF dotted line in Fig. 4). This length was taken with the help of a strip of doctor's tape which was pressed against the bone so that measurements of all the irregularities in the line were recorded. The tape was plastered along the anterior median line from the midpoint of sacral promontory to the midpoint of anterior inferior border of fifth sacral vertebra. Then it was divided with a pair of scissors at the designated points. After this it was taken off the sacrum and measured along a centimeter scale to find out the midventral curved length of sacrum.

Corporobasal index $=$ (Corpus width of S1) Breadth of base of sacrum)X100 [30]

Transverse diameter of the base of sacrum: It is the maximum transverse width of the superior surface of sacrum, comprising the superior surface of body of $S 1 \&$ two alae $(A B$ in 
Fig.3). It was measured with the help of divider.

Transverse diameter of Ist sacral vertebra: (Termed as corpus width by Fawcett, 1938 [30]). It was measured as the maximum transverse diameter of the articular surface of the body of first sacral vertebra (CD in Fig. 3) with the help of vernier calliper.

After completing measurements, calculating indices \& tabulating the data, it was statistically analyzed for range, mean \& standard deviation. Comparison of each of the indices was done by applying Student's ' $t$ ' test (unpaired) obtaining "p" value.

Fig. 1: Measurements of Pelvis.

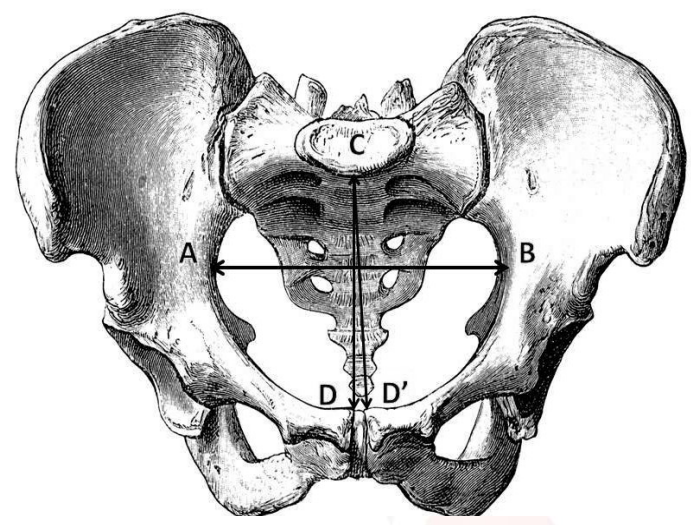

$C D, C^{\prime} D^{\prime}$ : Anatomical/True Conjugate

$A B$ : Transverse diameter of Inlet

Source: Authors Acknowlede in the references

Fig. 2: Measurements of Hip Bone.

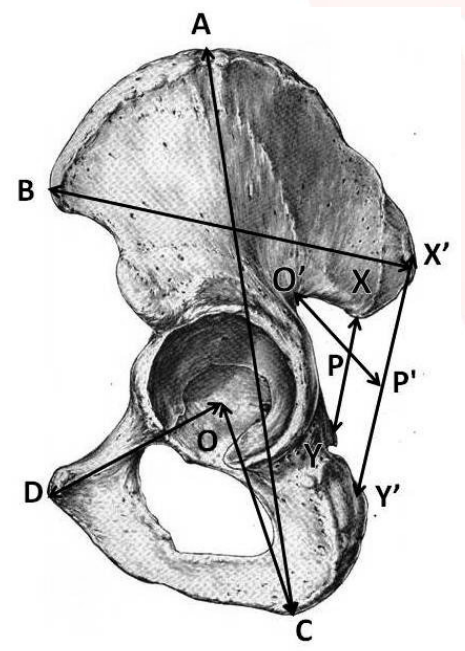

AC: Maximum Length of Hip Bone BX': Iliac Breadth $\mathbf{X}^{\prime} \mathbf{Y}^{\prime}$ : Base/ Width of GSN [Jovanvic \& Zivanovic Method (1965)] XY: Base/ Width of GSN [Singh \& Potturi Method (1978)] O'P': Depth of GSN [Jovanvic \& Zivanovic Method (1965)] O'P: Depth of GSN [Singh \& Potturi Method (1978)] XP: Posterior Segment Width of GSN [Jovanvic \& Zivanovic Method (1965)] X'P': Posterior Segment Width of GSN [Singh \& Potturi Method (1978)]

OD: Pubic Length OC: Ischial Length

Source: Authors Acknowlede in the references.
Fig. 3: Measurements of Hip Bone.

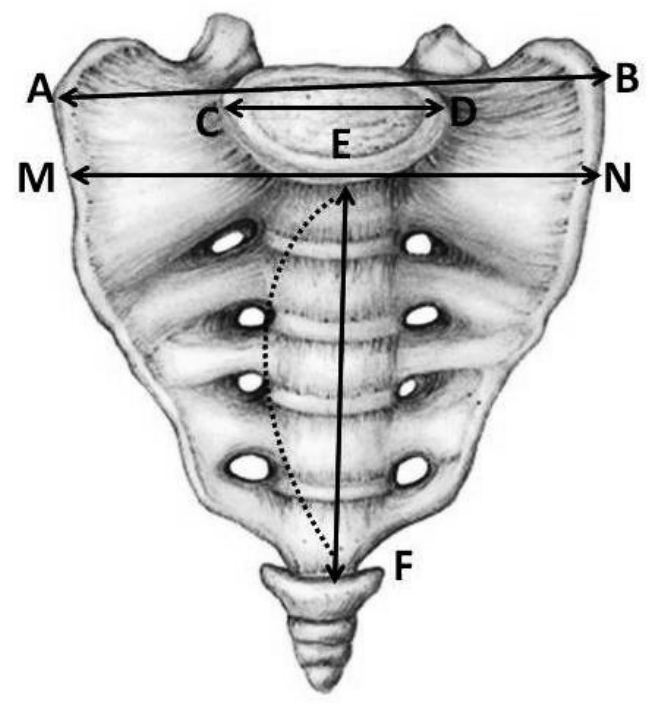

AB: Transverse diameter of Base of Sacrum CD: Transverse diameter of Body of S1 EF (Straight): Length of Sacral Axis EF (Curved): Midventral curved length of Sacrum MN: Anterior Straight breadth of Sacrum

\section{OBSERVATIONS}

The results of the various parameters measured in the study have been tabulated in Table 1 . Various indices were calculated using these parameters and their results have been tabulated in Table 2. It was found that amongst the calculated indices only pelvic brim index, Index I of Greater Sciatic Notch \& Longitudinal curvature of Sacrum were more in males as compared to females. Also the mean difference between the sexes was found to be significant for Coxal Index, Index I \& II of Greater Sciatic Notch, Ischiopubic Index \& Sacral Index.

Table 1: Values of various parameters used for calculation of Indices in the present study $(\mathrm{cm})$.

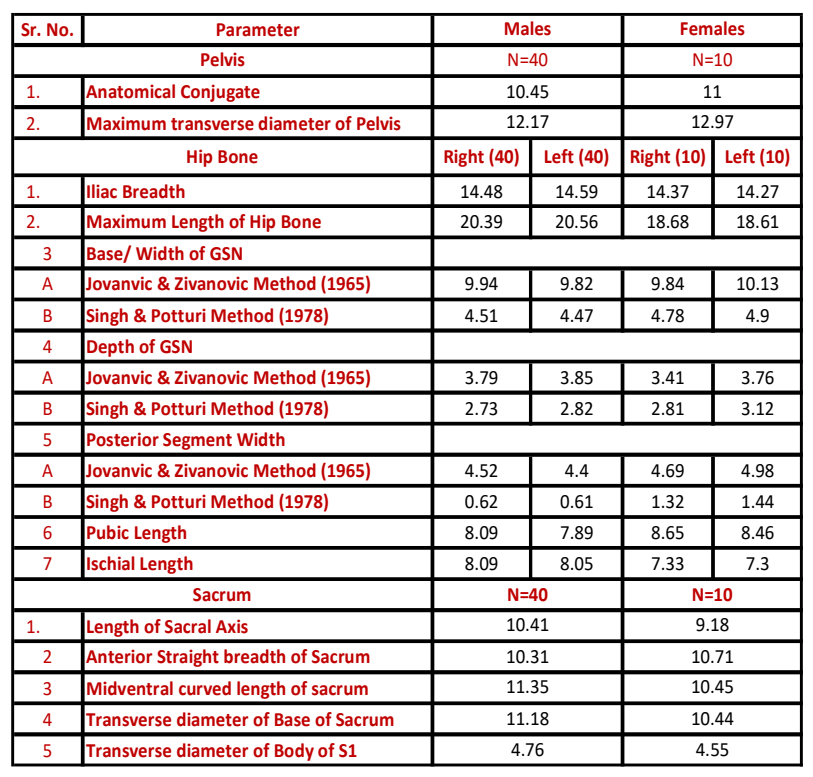


Table 2: Results of Indices calculated in the Present study.

\begin{tabular}{|c|c|c|c|c|c|c|}
\hline \multirow{2}{*}{ Sr. No. } & \multirow{2}{*}{ Index } & \multicolumn{2}{|c|}{ Males } & \multicolumn{2}{|c|}{ Females } & \multirow{2}{*}{ p-value } \\
\hline & & Right & Left & Right & Left & \\
\hline 1 & Pelvic Brim Index & $85.95 \pm 10.34$ & $85.91 \pm 9.82$ & $80.88 \pm 7.45$ & $75.13 \pm 6.09$ & 0.07 \\
\hline 2 & Coxal Index & $70.98 \pm 3.84$ & $70.98 \pm 3.73$ & $77.22 \pm 8.98$ & $76.92 \pm 9.13$ & 0 \\
\hline 3 & Index I of GSN & & & & & \\
\hline a. & Jovanvic \& Zivanovic Method (1965) & $38.30 \pm 4.44$ & $39.30 \pm 4.30$ & $34.71 \pm 2.47$ & $37.14 \pm 3.75$ & 0.007 \\
\hline B & Singh \& Potturi Method (1978) & $61.47 \pm 13.24$ & $63.96 \pm 10.78$ & $59.23 \pm 7.72$ & $63.46 \pm 5.65$ & 0.626 \\
\hline 4 & Index II of GSN & & & & & \\
\hline a. & Jovanvic \& Zivanovic Method (1965) & $45.58 \pm 4.31$ & $44.93 \pm 3.29$ & $47.83 \pm 6.43$ & $49.27 \pm 4.22$ & 0.002 \\
\hline b. & Singh \& Potturi Method (1978) & $13.69 \pm 1.35$ & $13.82 \pm 1.75$ & $27.83 \pm 4.70$ & $29.52 \pm 3.67$ & 0 \\
\hline 5 & Ischiopubic Index & $98.54 \pm 7.01$ & $98.02 \pm 7.62$ & $105.31 \pm 10.02$ & $103.17 \pm 12.52$ & 0.004 \\
\hline 6 & Sacral index & \multicolumn{2}{|c|}{$100.24 \pm 12.54$} & \multicolumn{2}{|c|}{$111.74 \pm 14.67$} & 0.016 \\
\hline 7 & Longitudinal Curvature index & \multicolumn{2}{|c|}{$91.59 \pm 6.43$} & \multicolumn{2}{|c|}{$87.87 \pm 5.67$} & 0.101 \\
\hline 8 & Corporobasal index & \multicolumn{2}{|c|}{$43.42 \pm 4.17$} & \multicolumn{2}{|c|}{$43.84 \pm 5.44$} & 0.788 \\
\hline
\end{tabular}

Table 3: Comparison Of Indices Of Greater Sciatic Notch [By Singh \& Potturi (1978) Method].

\begin{tabular}{|c|c|c|c|c|c|c|c|c|c|}
\hline \multirow{3}{*}{ Authors } & \multirow{3}{*}{ Race } & \multicolumn{4}{|c|}{ INDEX I } & \multicolumn{4}{|c|}{ INDEX II } \\
\hline & & \multicolumn{2}{|c|}{ Males } & \multicolumn{2}{|c|}{ Females } & \multicolumn{2}{|c|}{ Males } & \multicolumn{2}{|c|}{ Females } \\
\hline & & $\begin{array}{l}\text { Right } \\
\text { (n) }\end{array}$ & $\begin{array}{l}\text { Left } \\
\text { (n) }\end{array}$ & $\begin{array}{l}\text { Right } \\
\text { (n) }\end{array}$ & $\begin{array}{l}\text { Left } \\
\text { (n) }\end{array}$ & $\begin{array}{c}\text { Right } \\
\text { (n) }\end{array}$ & $\begin{array}{l}\text { Left } \\
\text { (n) }\end{array}$ & $\begin{array}{c}\text { Right } \\
\text { (n) }\end{array}$ & $\begin{array}{c}\text { Left } \\
\text { (n) }\end{array}$ \\
\hline Young \& Ince (1940) & London & \multicolumn{2}{|c|}{61.8} & \multicolumn{2}{|c|}{52.4} & \multicolumn{2}{|c|}{-} & \multicolumn{2}{|c|}{-} \\
\hline Davivongs (1963) & $\begin{array}{l}\text { Australian } \\
\text { Aborigines }\end{array}$ & \multicolumn{2}{|c|}{$55.68(100)$} & \multicolumn{2}{|c|}{$51.38(100)$} & \multicolumn{2}{|c|}{$13.45(100)$} & \multicolumn{2}{|c|}{$33.78(100)$} \\
\hline Singh \& Potturi (1978) & Varanasi & $65.12(60)$ & $64.48(60)$ & $53.69(40)$ & $53.03(40)$ & $15.00(60)$ & $14.61(60)$ & $32.81(40)$ & $33.70(40)$ \\
\hline Present Study & North Indians & $61.47(40)$ & $63.96(40)$ & $59.23(10)$ & $63.46(10)$ & $13.69(40)$ & $13.82(40)$ & $27.83(10)$ & $29.52(10)$ \\
\hline
\end{tabular}

Table 4: Comparison of Ischiopubic Index.

\begin{tabular}{|l|c|c|c|}
\hline \multicolumn{1}{|c|}{ Authors } & Race & Males (n) & Females (n) \\
\hline Washburn (1948) & Whites & $83.6(100)$ & $99.5(100)$ \\
\hline Washburn (1948) & Negroes & $79.9(50)$ & $95.0(50)$ \\
\hline Washburn (1949) & Bantu & $82.5(82)$ & $98.1(70)$ \\
\hline Washburn (1949) & Bushman & $83.7(26)$ & $100.0(29)$ \\
\hline Hanna \& Washburn (1953) & Eskimos & $83.9(129)$ & $98.8(95)$ \\
\hline Davivongs (1963) & $\begin{array}{c}\text { Australian } \\
\text { Aborigines }\end{array}$ & $77.98(89)$ & $92.72(72)$ \\
\hline Kimura K (1982) & Japanese & $60.4(52)$ & $70.7(51)$ \\
\hline Kimura K (1982) & American Whites & $61.4(50)$ & $72.4(52)$ \\
\hline Kimura K (1982) & American Blacks & $59.6(49)$ & $69.9(48)$ \\
\hline Pal et al (2004) & Uttar Pradesh & $89(62)$ & $100(143)$ \\
\hline Present Study & North Indian & $98.28(80)$ & $104.24(20)$ \\
\hline
\end{tabular}

Table 5: Comparison Of Sacral, Longitudinal Curvature \& Corporobasal Index.

\begin{tabular}{|c|c|c|c|c|c|c|c|}
\hline \multirow{2}{*}{ Authors } & \multirow{2}{*}{ Race } & \multicolumn{2}{|c|}{ Sacral Index } & \multicolumn{2}{|c|}{ Longitudinal Curvature Index } & \multicolumn{2}{|c|}{ Corporobasal Index } \\
\hline & & Males (n) & Females (n) & Males (n) & Females (n) & Males (n) & Females (n) \\
\hline Fawcett (1938) & Whites & - & - & - & - & 45.04 & 40.49 \\
\hline Fawcett (1938) & Blacks & - & - & - & - & 48.63 & 42.4 \\
\hline Young \& Ince (1940) & London & $108.9(494)$ & $109.8(489)$ & - & - & - & - \\
\hline Heyns (1944) & Bantu & - & $107.9(67)$ & - & $91.9(67)$ & - & - \\
\hline Francis (1952) & European & 112 & 116 & - & - & - & - \\
\hline Sowri (1952) & South Indian & - & $109.8(34)$ & - & $85.51(34)$ & - & - \\
\hline Davivongs (1963) & $\begin{array}{l}\text { Australian } \\
\text { Aborigines }\end{array}$ & $104.16(50)$ & $115.49(50)$ & $92.46(50)$ & $90.80(50)$ & $47.42(50)$ & $43.62(50)$ \\
\hline Raju et al (1980) & Varanasi & $100.85(33)$ & $111.39(11)$ & $92.77(33)$ & $88.51(11)$ & $44.94(33)$ & $40.96(11)$ \\
\hline Ahankari \& Ambali (2016) & Maharashtra & - & - & $92.36(150)$ & $83.47(150)$ & $44.57(150)$ & $41.41(150)$ \\
\hline Joshi \& Puranic (2016) & Maharshtra & 102.31 & 117.58 & 90.89 & 89.14 & - & - \\
\hline Present Study & North Indian & $100.24(40)$ & $111.74(10)$ & $91.59(40)$ & $87.87(10)$ & $43.42(40)$ & $43.84(10)$ \\
\hline
\end{tabular}




\section{DISCUSSION}

Pelvic Brim Index: As can be seen in Table 2, this was found to be significantly more in males in the present study. When compared with previous authors it was seen that while Orford, 1934 [31] found it to be higher in Bush females [Males $=97.7$, females $=105.2$ ] Young \& Ince, 1940 [32] found so in London males [Males= 99.2, Females $=93.9$ ]. Thus our results are in consonance with Young \& Ince (1940) [32]. Supporting their results, Young \& Ince (1940) [32] have aptly put forward the view that as the greatest transverse diameter of the pelvic brim in the male pelvis is relatively diminished than the true conjugate in comparison with the corresponding diameters of the female pelvis, the ratio of true conjugate to the transverse diameter or the pelvic brim index is greater in the former. They also emphasized that while the pelvic brim index undoubtedly indicates the general shape of pelvic inlet, viz. as to whether it tends to be circular or is oval with the major axis in sagittal or transverse direction \& the degree of flattening in these planes, it does not differentiate wedge shaped or android type of inlet.

Jordaan (1976) [33] when comparing the human with other eutheria, noted a decrease in proportionate value of antero-posterior diameter relative to transverse diameter of pelvic inlet i.e. the brim index. This decrease in antero-posterior diameter was attributed by him primarily to three factors viz.-

\section{i. Reduction of size of ilium \\ ii. Differential growth of ilium \\ iii. Increased sacral width in man}

Coxal Index: It was found to significantly more in females in the present study ( $p$-value $=0.000)$ [Table 2]. Earlier, Davivongs (1963) [20] calculated this index in Australian Aborigine races \& found it to be $74.77 \pm 3.41$ (Range $70.1-80.9$ ) in males \& $78.04 \pm 3.09$ (Range $71.1-83.7$ ) in females while Siddapur et al (2014) [34] calculated this index in Tamil Nadu population \& gave values of $67.7 \pm 2.6$ in males \& $70.8 \pm 1.2$ in females. Thus both found it to be more in females as compared to males \& racial variations can be seen in the results

Phylogeny: Jordaan (1976) [33] threw a flood of light on changing values of Coxal Index in different Eutheria i.e. 42.8 in chimpanzee, 55.3 in gorilla, 70 in human fetus \& 74-90 in man. This was attributed to both diminishing length \& increasing width of ilium consequent upon the transition from quadrupedal to permanent erect posture in man. He further emphasized that this difference in iliac blade of man and monkeys or apes is especially evident in posterior portion.

Indices of Greater Sciatic Notch: As all the measurements of Greater Sciatic Notch were taken according to the methods of two different authors, hence the indices of the notch were also calculated separately for the two respective methods

* Index- I of Greater Sciatic Notch: By both methods it was more in males but the difference was statistically significant only by Jovanovic \& Zivanovic (1965) ${ }^{23}$ method. [Tab.2] A comparison of Index-I with those of previous studies [Table 3] showed that it is more in males as compared to females in all the races. But in the present study a greater degree of overlap is seen between male and female values probably due to the smaller female sample size. While Davivongs (1963) ${ }^{20}$ found significant sex difference between the means, it was neither true in Singh \& Potturi (1978) ${ }^{25}$ study and nor in the present study ( $p$-value $=0.626)$.

\section{* Index- II of Greater Sciatic Notch:}

It was significantly higher in females by both methods [Table 2]. Earlier Davivongs (1963) [20] \& Singh \& Potturi (1978) [25] also studied it in Australian Aborigine and Varanasi population respectively and found it to be more in females [Table 3]. All the results supplement Jovanovic \& Zivanovics' (1965) [23] statement that it is the relation between the upper and lower segments of the notch that is more important in sex determination than the width or depth of the notch.

Ischiopubic Index: In the present sample the mean Ischiopubic index was found to be significantly more in females [Table 2].

The results of the present study are in consensus with other authors [Table 4]. This index was named as "Washburn Index" by Washburn (1948) [35] who documented its use for sexual dimorphism as the difference in the length of ischium 
is roughly proportional to the difference in size but the pubic bone is proportionately longer in females as it is most responsive to female sex hormones. Washburn (1949) [36] also emphasized that the ischiopubic index and width of greater sciatic notch, can ascertain the sex of over $98 \%$ of skeletons.

Sacral index: In the present study, the mean sacral index was significantly more in females [Table 2]. It has been found to be more in females in all the previous studies too [Table 5]. However racial variations in the two sexes are apparent from the table.

Longitudinal curvature index: This was found to be more in males as compared to females, but the mean difference was statistically insignificant. A comparison with previous studies shows that the longitudinal curvature index is more in males as compared to females in all the races [Table 5], supplementing Davivongs' (1963) [20] view that the higher values of this index in males indicates that the anterior surface of female sacrum is more pronounced. However the difference between the sexes was found to be statistically significant by all authors.

Corporobasal index: This index was more in females, however the difference was statistically insignificant. This was in contrast to Fawcett (1938) [30] (Whites \& blacks), Davivongs, 1963 [20] (Australian Aborigines), Raju et al (1980) [37] (Varanasi), Ahankari \& Ambali $2016[38]^{8}$ (Maharashtra) \& Joshi et al, 2016 [16] (Maharashtra) who found the corporobasal index to be significantly more in males as compared to females [Table 5]. This discrepancy may be due to the smaller female sample size. A closer look at tables 3,4 \& 5 show that although the inference of results of present study are quite similar to the previous studies but at the same time a great volume of regional differences can be seen in all the indices hence advocating a need for region specific data for all populations.

\section{CONCLUSION}

Anthropometric characteristics have direct relationship with sex, shape and form of an individual and these factors are intimately linked with each other and are manifestation of the internal structure and tissue components which in turn, are influenced by environmental and genetic factors. At the end, the long and the short of the study is that the pelvis exhibits a wide range of racial as well as regional variations in both morphological and morphometrical features, moreso in the latter. So, a baseline data is required for all the populations for future comparisons.

\section{Conflicts of Interests: None}

\section{REFERENCES}

[1]. Holobinko A. Forensic human identification in the United States and Canada: A review of the law, admissible techniques, and the legal implications of their application in forensic cases. Forensic Sci Int 2012; 222(1):394.

[2]. Lake A, James H, Berketa J. Disaster victim identification: quality management from an odontology perspective. Forensic Sci, Med and Pathol 2012; 8(2):157-63.

[3]. Schuliar Y, Knudsen PJT. Role of forensic pathologists in mass disasters. For Sci, Med and Pathol 2012; 8(2):164-73.

[4]. Dixit SG, Kakar S, Agarwal S, Choudhry R. Sexing of human hip bones of Indian origin by discriminant function analysis. J Forensic Leg Med 2007;14(7):42

[5]. Kamal AHM, Ara S, Begum S, Hoque M \& Khatun K. Sexual Dimorphism in Alar Length and Auricular Index of Sacrum. Bangladesh J Anat 2014; 12(1): 17-21.

[6]. Shah T, Patel M, Nath S, Menon SK. A model for construction of height and sex from shoulder width, arm length and foot length by regression method. J Forensic Sci \& Criminology. 2015; 3(1):102.

[7]. Rao CR. In: Advanced statistical method in biometric research. John Wiley and Sons, Inc. London; 1962:291-296.

[8]. Trancho I, Robledo B, Bueis I, Sanchez A. Sexual determination of femur using discriminant functions: Analysis of a Spanish population of known sex and age. J Forensic Sci 1997; 42(2):181-185.

[9]. Abitbol MM. Obstetrics and posture in pelvic anatomy. J Hum Evol 1987; 16: 243-255.

[10]. Schultz AH. Sex differences in the pelvis of primates. Amer J Phys Anthropol 1949; 7: 401-423.

[11]. Tague RG. Sexual dimorphism in the human bony pelvis, with a consideration of the Neandertal pelvis from Kebara Cave, Israel. Amer J Phys Anthropol 1992; 88: 1-21.

[12].Drake RL, VogI W, Mitchell AWM. Pelvis and perineum. In: Gray's Anatomy for students. London: Elsevier Churchil Livingston 2005:386-87.

[13]. Steyn M and Iocan MY. Metric sex determination from the pelvis in modern Greeks. Forensic Sci Int 2008;179(1):86.e1-6

[14]. Williams and Warwick. In: Gray's Anatomy 38th edn; 1995:528-31. 
[15]. Issac B. Biometry of the posterior border of the human hip bone: normal values and their use in sex determination. J Anat Soc India 2002; 51: 43-46.

[16]. Joshi UU et al. Various sacral indices: role in study of sexual dimorphism. Int J Res Med Sci. 2016;4(3):841-846

[17]. Franklin D, Freedman L, Milne N. Sexual dimorphism and discriminant function sexing in indigenous South African crania. HOMO-J Comparative Hum Biol 2005; 55(3):213-28.

[18]. Franklin D, Cardini A, Oxnard CE. A geometric morphometric approach to the quantification of population variation in sub Saharan African crania. Amer J Hum Biol 2010; 22(1):23-35.

[19]. Turner W. The index of pelvic brim as a basis of classification. J Anat Physiol Lond 1886; 20: 12543

[20]. Davivongs V. The pelvic girdle of the Australian Aborigine; sex differences and sex determination. Am J Phys Anthropol 1963; 21: 443-56.

[21]. Seidler H. Sex-diagnosis of isolated os coxae by discriminant functions. J Human Evol 1980; 9: 597600.

[22]. Stewart TD. Hrdlicka's Practical Anthropolometry. $4^{\text {th }}$ Edition. Philadelphia, Wistar Institute of Anatomy and Biology, 1952: 127-132.

[23]. Jovanovic S and Zivanovic S. The establishment of the sex by the great sciatic notch. Acta Anat 1965; 61: 101-107.

[24]. Day MH, Wilmott RW. Sexual differentiation in the innominate bone studied by multivariate analysis. Annals Human Biol 1975; 21: 143-151.

[25]. Singh S, Potturi BR. Greater sciatic notch in sex determination. J Anat 1978; 125(3): 619-624.

[26]. MacLaughlin SM, Bruce MF. The sciatic notch/acetabular index as a discriminator of sex in European skeletal remains. J Forensic Sci 1986; 31(4): 1380-1390.
[27]. Thieme FP. Sex in Negro skeletons. J Forensic Med 1957; 4(2): 72-84. Cited by Krogman WM. Sexing skeletal remains: Sex differences in the pelvis. In: The human skeleton in forensic medicine. Springfield, Illinos, USA: Charles C Thomas; 1962: 122142.

[28]. Wilder HH. A laboratory Manual of Anthropometry. Philadelphia P, Blakistan 1920. Cited by Davivongs V. The pelvic girdle of the Australian Aborigine; sex differences and sex determination. Am J Phys Anthropol 1963; 21: 443-56.

[29]. Radlauer. Beitrage zur Anatomie des Kreuzbeines. Morphol Jahrs 1908; 38: 323-447.

[30]. Fawcett E. The sexing of human sacrum. J Anat 1938; 72: 633.

[31]. Orford M. The pelvis of Bush race. S Afr J Sci 1934; 31: 586-610. Cited by Heyns OS. A study of Bantu female pelvis. J Anat Lond 1944; 73: 151-165.

[32]. Young $M$ and Ince JGH. A radiographic comparison of the male and female pelvis. J Anat 1940; 74: 37485.

[33]. Jordaan HVF. The differential development of the hominid pelvis. S Afr Med J 1976; 50: 744-748.

[34]. Siddapur KR et al. Int J Res Med Sci. 2014 Nov;2(4):1526-1529

[35]. Washburn SL. Sex differences in the pubic bone. Am J Phys Anthropol 1948; (6): 199-207.

[36]. Washburn SL. Sex differences in the pubic bone of Bantu and Bushman. Am J Phys Anthropol 1949; (7): 425-432.

[37]. Raju PB, Singh S, Padmanabhan R. Sex determination and sacrum. J Anat Soc Ind 1980; 30(1): 13-15.

[38]. Ahankari RS \& Ambali MP. Sexual Dimorphism in Human Sacrum in Maharshtra Population. Ind J Clin Anat Physiol 2016;3(1):91-96.

How to cite this article:

Kanika Sachdeva, Rajan Kumar Singla, Gurdeep Kalsey. METRIC ANALYSIS OF SEXUAL DIMORPHISM IN NORTH INDIAN PELVIC INDICES. Int J Anat Res 2019;7(2.1):6353-6360. DOI: 10.16965/ ijar.2019.118 